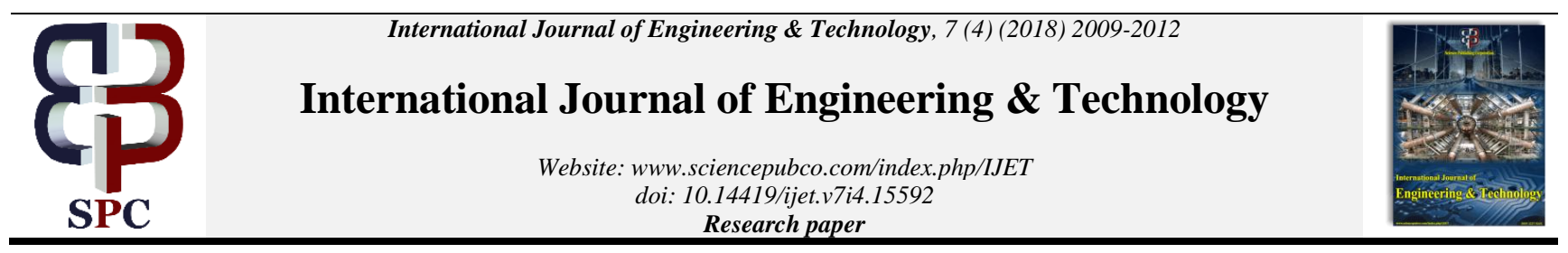

\title{
Water content effect on biofilm formation and bio-corrosion process in biodiesel-diesel storage tank
}

\author{
Aida Nur Ramadhani ${ }^{1}$ *, Ardiyan Harimawan ${ }^{1}$, Hary Devianto ${ }^{1}$ \\ ${ }^{1}$ Chemical Engineering Department, Faculty of Industrial Technology, Institut Teknologi Bandung Bandung 40132 Indonesia \\ *Corresponding author E-mail:
}

\begin{abstract}
This study focused in the effect of water content on biofilm and bio-corrosion, and knowing its influence on biodiesel-diesel blends' quality. Biodiesel is hygroscopic and less stable, makes this fuel needs more attention in storing. Fuel is usually stored in a storage tank of carbon steel which easily corroded by microorganisms, such as Bacillus megaterium. Corrosion occurs because microorganisms use fuel as nutrients and water content in hygroscopic biodiesel supports to grow and metabolize. Experiments were carried out by immersing carbon steel in medium 30\% biodiesel (B30) for 21 days with water content variation of $0 \%, 5 \%$, and $10 \%$ volume. The number of colonies in biofilms increased up to 1,3 times in a $10 \%$ water content. A uniform biofilm provides an inhibitory effect on corrosion per time, also layer of iron phosphate formed on water content variation, so the highest $0.642 \pm 0.28 \mathrm{~mm} /$ year on $0 \%$ water content. $\mathrm{Fe}_{2} \mathrm{O}_{3}, \mathrm{Fe}_{3} \mathrm{O}_{4}$, and $\mathrm{FeOOH}_{\text {are the }}$ corrosion product by Bacillus megaterium. The highest biodegradation efficiency achieved by variation water content both $5 \%$ and $10 \%$ were $68.5 \%$ and $67.23 \%$, and then followed by no water content at $60.40 \%$.
\end{abstract}

Keywords: Bacillus Magisterium; Bio Corrosion; Biodiesel; Biofilm; Degradation; Water Content.

\section{Introduction}

World energy demand, especially for petroleum oil as a fuel, has increased significantly every year. Petroleum fuel (BBM) dominates national energy demand by $31.2 \%$ by 2015 , and will increase to $40.7 \%$ by 2050 (BPPT, 2016). In 2016, Indonesia needs 14 million kiloliters of fuel oil (BPH Migas, 2016). Therefore, innovation and development of alternative energy is needed.

One of the potential alternative fuels in Indonesia is biodiesel. Biodiesel can be produced from natural raw materials, such as palm oil. Palm oil itself is the largest commodity in Indonesia, which is 31,284.30-kilo tons production in 2015 (BPS, 2017). In its application as a fuel, biodiesel can be mixed with petroleum diesel or often referred to as diesel. The use of biodiesel as a fuel mixture has been regulated by the government in ESDM Ministerial Regulation No.12 of 2015, which in 2025 will use $30 \%$ of biodiesel. Different biodiesel properties with diesel fuel make more attention to maintaining fuel quality.

Biodiesel has high cetane number, biodegradable, and low emissions, but more unstable than diesel (Fazal et al.,2010; Haseeb et al., 2010; Jakeria et al.,2014; Lohani, et.al. 2014, Akpor, et. al. 2014; Adebayo and Oluwadare, 2014 ). The content of unsaturated fatty acids makes biodiesel susceptible to oxidation (Monyem and Gerpen, 2001). In addition, the hygroscopic nature of biodiesel causes high water content dissolved in biodiesel (Fregolente et al., 2012; He et al., 2007). This dissolved water content in certain conditions will precipitate to the bottom of the tank. This process will repeat continuously until it forms a layer of free water at the bottom of the tank. The presence of this free water layer can trigger the formation of sludge that can obstruct the system (He et al., 2007). On the other hand, water may increase the growth of microorganisms that can trigger corrosion (Groysman, 2014).
Frequently used fuel storage method is the ground storage tank. Storage tanks are generally made of carbon steel. Carbon steel is easily fabricated, protect biodiesel from exposure to sunlight, and its price is cheaper than stainless steel (Groysman, 2014; Komariah et al, 2017; Restrepo-Florez et al, 2014). However, carbon steel has a weakness that is easily corroded, either chemically or by microorganisms because stainless steel has more protective action of chromium and nickel elements (Heyer et al., 2013; Adebayo et al., 2014; Kovács et al., 2015).

Corrosion is an interaction reaction between the metal and its environment, occurs because of the tendency of the metal to return to its original condition, the oxidant state in nature (Zarasvand and Rai, 2014; Beech and Sunner, 2004). Corrosion contributes to the destruction of industrial piping and storage systems. Approximately $20 \%$ of petroleum product leakage is caused by corrosion in the tank (Groysman, 2014). Corrosion processes that occur include chemical and biological corrosion. Biologically, corrosion is caused by the activity of microorganisms that play a role in corrosion mechanism. One of the role of microorganisms in corrosion is by the formation of biofilms on the metal surface.

Biofilm is one of the survival strategies of microorganisms. Microorganisms use fuel as a carbon source and water to grow and metabolize. Carbon steel is one type of metal that is easily corroded because of its tendency to form an oxide layer which is the ideal place for the attachment of microorganisms (Heyer et al., 2013). The existence of this biofilm causes a non-uniform oxygen concentration on the metal surface (Lewandowski and Beyenal, 2008). Biofilm-enclosed areas will be oxygen deprived and an anaerobic anodic condition, and vice versa to cathodic conditions. This results is a potential difference from anodic to cathodic, and then corrosion occurs.

One of the microorganisms that have been studied survive on hydrocarbon medium is Bacillus megaterium. B. megaterium is found in pipelines and hydrocarbon storage systems, causing corrosion 
and degradation of fuels (Das and Chandran, 2011; Maruthamuthu et al., 2011; Rajasekar et al., 2005). This research was conducted to determine the activity of $B$. megaterium in mixed-fuel biodiesel fuel medium with various water concentrations added in biodiesel.

\section{Experimental}

\subsection{Materials}

FAME biodiesel from palm oil was produced by Chemical Engineering ITB Laboratory and diesel or diesel petroleum from Pertamina. The specimens and microorganism used in this research were carbon steel and Bacillus megaterium from Chemical Engineering ITB Laboratory.

\subsection{Preparation of Test Solution (immersing medium)}

The test solution was FAME biodiesel and diesel sterilized with $0.45 \mu \mathrm{m}$ pore size membrane.

\subsection{Preparation of Bacillus megaterium}

The growth medium used for $B$. megaterium was Bushnell Haas (BH) consist of $\mathrm{MgSO}_{4} 0,2 \mathrm{~g} / \mathrm{L}, \mathrm{CaCl}_{2} 0,02 \mathrm{~g} / \mathrm{L}, \mathrm{KH}_{2} \mathrm{PO}_{4} 1 \mathrm{~g} / \mathrm{L}$, $\mathrm{K}_{2} \mathrm{HPO}_{4} 1 \mathrm{~g} / \mathrm{L}, \mathrm{NH}_{4} \mathrm{NO}_{3} 1 \mathrm{~g} / \mathrm{L}, \mathrm{FeCl}_{3} 0,05 \mathrm{~g} / \mathrm{L}$. NaOH was added to maintain $\mathrm{pH}$ neutral. To increase the number of microorganism, B. megaterium were cultured in a sterilized $\mathrm{BH}$ medium with a working volume of $100 \mathrm{ml}$ until it enters a stationary growth stage. Furthermore, the acclimatization process conducted in medium Bushnell Haas $300 \mathrm{ml}$ and adding $1 \mathrm{~g}$ diesel as carbon source, then inoculated with microbial culture $2 \mathrm{ml}$. Incubation done in the rotary shaker at $27^{\circ} \mathrm{C} 200 \mathrm{rpm}$ for 30 days.

\subsection{Preparation of reactor and metal}

The reactor used was a square box and a cap made of acrylic with a working volume of $800 \mathrm{ml}$. On the lid there were a number of glass hooks with metal specimens. The amount of metal calculated according to ASTM G 31-72 standard with size $1 \times 1 \mathrm{~cm}$. ST-37 carbon steel were used as metal specimens, polished with abrasive paper from 240 to 1200 grids.

\subsection{Experimental}

The corrosion process simulation was done by immersing carbon steel metal specimens in a fuel mixture medium with $30 \%$ biodiesel. The addition of water content consisted of three variations: B30-0 (without water addition), B30-5 (with 5\% water addition), and B3010 (with $10 \%$ water addition). The metal specimens were hung in a hook from glass. In variation of water addition, the metal were hung at the interface between fuel and water. The reactor then stored at room temperature for 21 days.

\subsection{Characterization}

Analysis of this study included analysis of bacterial colonies on biofilm by TPC method, corrosion rate with gravimetric method, corrosion product with XRD, and biofilm composition with FTIR. Degradation of mixed fuel also analyzed by GCMS.

\section{Results and discussion}

\subsection{Growth of microorganisms in biofilms}

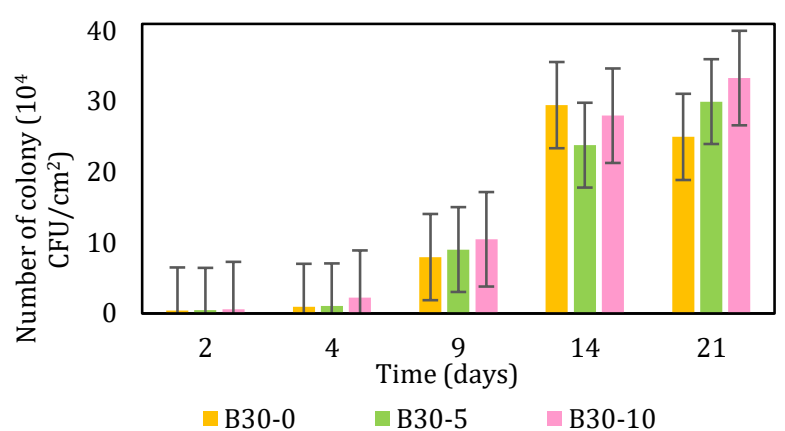

Fig. 1: Growth Profile of Microorganism in Biofilms.

Growth profile of Bacillus megaterium colony on medium B30 with variations of water addition is presented in Figure 1. In the three variations, the adaptation phase ran fast, which on the $9^{\text {th }}$ day of growth has entered the exponential phase. Differences began to appear on the last day of submersion, where variations without additional water decreased the number of colonies. This decrease was caused by biofilms which undergoes lysis phase. In the variation with the addition of water, the growth profile has not decreased, indicating the absence of lysis. The number of colonies actually grew over time immersion.

The addition of water into the medium increased the volume of free water that can be utilized by microorganisms. The free water in the hydrocarbon medium can trigger the growth of microorganisms, and may increase the risk of corrosion and degradation of hydrocarbons (Kamiński and Kurzydłowski, 2008). Degradation of esters in biodiesel is one result of the presence of water in the medium (Jakeria, Fazal dan Haseeb, 2014).

The presence of a layer of iron oxide on the metal surface, caused the tendency of microorganisms to attach to the metal. This attaching process was an initiation of biofilm formation. The more water added with mineral content, the more number of colonies of microorganisms in the biofilm are attached. The interface layer between water and metal surfaces was a strategic place for microorganisms' growth than the bulk medium (Rajasekar and Ting, 2011). Nutrients were absorbed in the metal made the microorganisms prefer to grow on metal surfaces (Heyer et al., 2013).

In addition, the addition of water also inhibits lysis when compared to variations without adding water. It was due to the nutrients on the metal surface causing the increasing tendency of the active cells to adhere to the metal surface. The active cells accumulated on the metal surface, then shifted the dead cells.

\subsection{Corrosion rate}

The corrosion rate was calculated by the weight difference of carbon steel specimens before and after immersion process. Can be seen in Figure 2, the highest corrosion rate was achieved by medium B30 without addition of water, followed by variation with $5 \%$ then $10 \%$ water additions. The corrosion rate is increased due to the activity of microorganisms that produce acidic metabolite products such as carboxylic acids, aldehydes, alcohols and saturated fatty acids (Jakeria et al., 2014; Sousa et al., 2009). This metabolite product accumulated on the surface causing an increase in corrosion rate. Biofilms covered metal, causing microorganisms had difficulty accessing the medium as a carbon source and utilizing electrons from iron oxidation as electron donors (Xu and $\mathrm{Gu}, 2014)$, resulting an increase in mass loss during immersion time. 


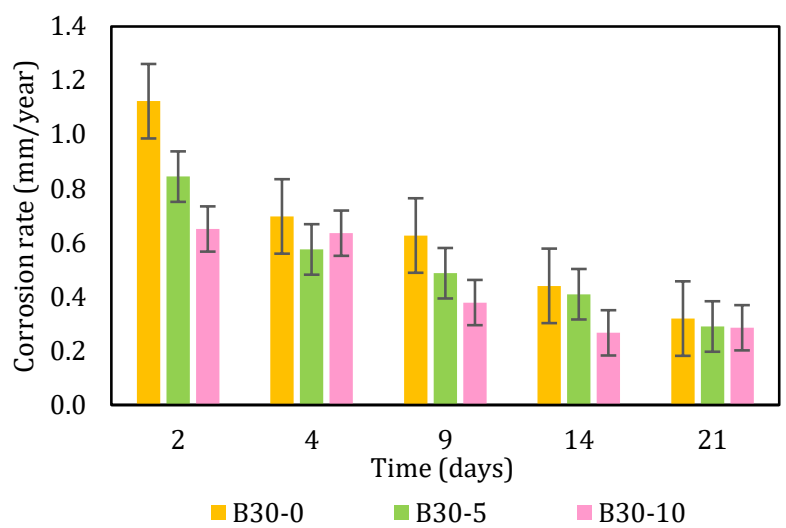

Fig. 2: Corrosion Rate of Carbon Steel.

The observations also show that there was a decrease in corrosion rate per time of immersion. This decrease was proportional to the increase in the number of colonies of microorganisms in biofilms per time which giving an inhibitory effect on corrosion. Biofilms were formed evenly on the metal surface, minimized contact between metal specimens with oxidative medium environments, which can oxidize metals and resulted corrosion. The high rate of corrosion at the beginning of immersion was due to the lack of biofilm at the beginning. The contact between metal and oxidative medium environments was inevitable, then metal oxidation occurred. In addition, the decrease in corrosion rate in the variation of water addition was also due to the protective layer on the surface of the metal specimen. The metal was placed on the interface layer, had direct contact with two mediums, organic in the form of hydrocarbons and inorganic form of water and minerals. This coating was a result from reactions of soluble $\mathrm{Fe}$ in inorganic medium, ie with $\mathrm{K}_{2} \mathrm{HPO}_{4}$ and $\mathrm{KH}_{2} \mathrm{PO}_{4}$ (Rajasekar and Ting, 2011). Results of SEM biofilms on the 11th day showed the presence of phosphate iron coating presented in Figure 3.

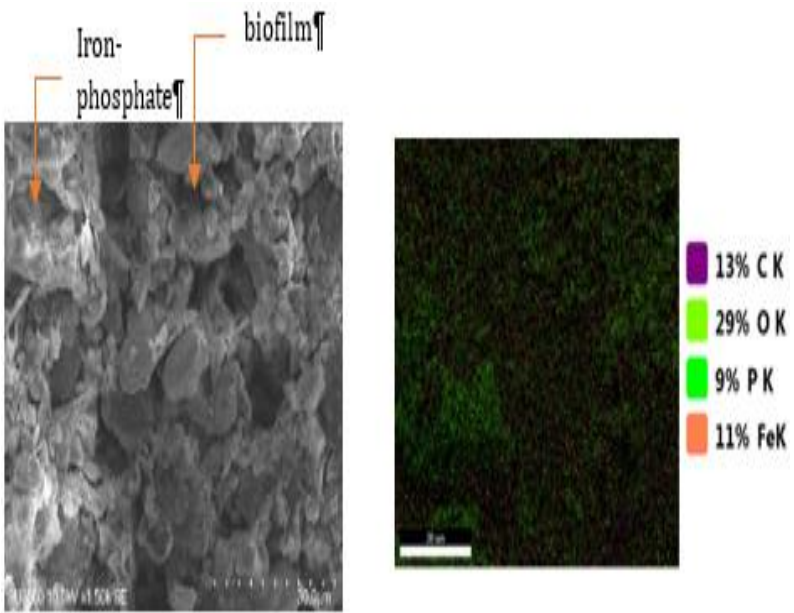

Fig. 3: Iron-Phosphate Layer at Surface of Carbon Steel Analyzed by SEM And SEM EDAX at $10 \%$ Water Content Variation.

\subsection{Corrosion product}

Carbon steels can be oxidized to $\mathrm{Fe}^{2+}$. These ions can be utilized Bacillus megaterium as an electron donor in metabolic reactions. Microorganisms also can convert it into $\mathrm{Fe}^{3+}$ to form iron oxide hydrate compounds by utilizing oxygen as an electron acceptor. The corrosion products are iron oxide, $\mathrm{Fe}_{2} \mathrm{O}_{3}$ and $\mathrm{Fe}_{3} \mathrm{O}_{4}$.

Medium diesel and biodiesel which is a hydrocarbon organic compound cause increase solubility of iron into ion, and caused corrosion (Rajasekar et al., 2011). The free water added in the medium, reacted with the $\mathrm{Fe}$ and oxygen ions produced a corrosion product FeOOH (Heyer et al., 2013; Jones, 1986). Therefore on variations of water addition detected the presence of $\mathrm{FeOOH}$ corrosion product, whereas in the variation without addition of water was not.

\subsection{Degradation efficiency}

The observations were made using GCMS (Gas chromatographymass spectrometry) analysis by comparing the compositions before and after the inoculation of Bacillus megaterium. In the variation of water addition to medium B30, BE number was $60.40 \%$ for B30-0, and were $68.5 \%$ and $67.23 \%$ for B30-5 and B30-10. It could be said that biodiesel degradation not only caused by auto oxidation, but also caused by the addition of water. As mentioned by Kamiński and Kurzydłowski, free water in fuel increased the growth of microorganism and caused degradation.

The \%BE value in the mixed medium was a combination of solar degradation by the activity of Bacillus megaterium and the degradation of biodiesel from the auto oxidation process. The degradation of esters in biodiesel was also one result of the presence of water in the medium (Jakeria et al., 2014).

\section{Conclusion}

From the research that has been done can be drawn some conclusions are:

1) The addition of water to the mixed medium of diesel and biodiesel affected the growth of microorganisms, where higher water levels lead to an increase in the number of colonies of microorganisms.

2) The formation of biofilms provided inhibition effect against corrosion, the corrosion rate decreased with time of immersion. Addition of water caused formation of an iron-phosphate layer which also gave an inhibitory effect on corrosion.

3) A study of the effect of water content on biodiesel stability on mixed media in various concentrations is required, especially between B30 - B100.

\section{Acknowledgments}

Authors would like to express their gratitude especially to the Indonesia Endowment Fund for Education LPDP Scholarship, which has provided research fund, Chemical Engineering Program of Institut Teknologi Bandung which has provided facilities and infrastructure in the implementation of this research, staff of Microbiology and Technology Laboratory of Bioprocess for the assistance given during the research.

\section{References}

[1] Adebayo, A., \& Oluwadare, B. S. 2014. Corrosion of Steels in Water and Hydrogen Sulphide. Review of Industrial Engineering Letters, 1(2), 80-88. https://doi.org/10.18488/journal.71/2014.1.2/71.2.80.88

[2] Akpor, O. B., Vincent, T. Z., \& Olalekan, A. P. 2014. Investigation of the Role of Two Bacterial Species in the Removal of Sulphate from Wastewater. The International Journal of Biotechnology, 3(11), 138-150.

[3] Alasvand Zarasvand, Kiana dan V. Ravishankar Rai. 2014. "Microorganisms: Induction and inhibition of corrosion in metals." International Biodeterioration and Biodegradation 87:66-74. Diambil (http://dx.doi.org/10.1016/j.ibiod.2013.10.023).

[4] Beech, Iwona B. dan Jan Sunner. 2004. "Biocorrosion : towards understanding interactions between biofilms and metals." Current Opinion in Biotechnology 15:181-86. https://doi.org/10.1016/j.copbio.2004.05.001

[5] BPPT. (2016): Indonesia Energy Outlook 2016.

[6] Das, Nilanjana dan Preethy Chandran. 2011. "Microbial Degradation of Petroleum Hydrocarbon Contaminants: An Overview." Biotechnology Research International 2011:1-13. Diambil (http://www.hindawi.com/journals/btri/2011/941810/).

[7] Fazal, M. A., A. S. M. A. Haseeb, dan H. H. Masjuki. 2010. "Comparative corrosive characteristics of petroleum diesel and palm biodiesel for automotive materials." Fuel Processing Technology 91(10):1308-15.

Diambil 
[8] Fregolente, Patricia Bogalhos Lucente, Leonardo Vasconcelos Fregolente, dan Maria Regina Wolf MacIel. 2012. "Water Content in Biodiesel, Diesel, and Biodiesel-Diesel Blends." Journal of Chemical and Engineering Data 57(6):1817-21. https://doi.org/10.1021/je300279c.

[9] Groysman, Alec. 2014. Corrosion in Systems for Storage and Transportation of Petroleum Products and Biofuels. London: Springer Dordrecht Heidelberg New York London. https://doi.org/10.1007/978-94-007-7884-9.

[10] Haseeb, A. S. M. A., H. H. Masjuki, L. J. Ann, dan M. A. Fazal. 2010. "Corrosion characteristics of copper and leaded bronze in palm biodiesel." Fuel Processing Technology 91(3):329-34. Diambil (http://dx.doi.org/10.1016/j.fuproc.2009.11.004).

[11] He, B. B., J. C. Thompson, D. W. Routt, dan J. H. Van Gerpen. 2007. "MOISTURE ABSORPTION IN BIODIESEL AND ITS PETRODIESEL BLENDS.” American Society of Agricultural and Biological Engineers 23(2):71-76.

[12] Heyer, A. et al. 2013. "Ship ballast tanks a review from microbial corrosion and electrochemical point of view." Ocean Engineering 70:188-200

Diambil (http://dx.doi.org/10.1016/j.oceaneng.2013.05.005)

[13] Jakeria, M. R., M. A. Fazal, dan A. S. M. A. Haseeb. 2014. "Influence of different factors on the stability of biodiesel: A review." Renewable and Sustainable Energy Reviews 30:154-63. https://doi.org/10.1016/j.rser.2013.09.024.

[14] Jones, J. Gwynfryn. 1986. "Iron Transformations by Freshwater Bacteria." Hal.149-85 in Advances in Microbial Ecology, diedit oleh K C. Marshall. Boston, MA: Springer US. Diambil (https://doi.org/10.1007/978-1-4757-0611-6_4).

[15] Kamiński, J. dan K. J. Kurzydłowski. 2008. "Use of impedance spectroscopy on testing corrosion resistance of carbon steel and stainless steel in water-biodiesel configuration." Warsaw University of Technology, Faculty of Materials Science \& Engineering 141.

[16] Komariah, Leily Nurul, Sucia Aprisah, dan Yangia S. L. Rosa. 2017 "Storage tank materials for biodiesel blends; the analysis of fuel property changes.” MATEC Web of Conferences 02012.

[17] Kovács, A., J. Tóth, Gy Isaák, dan I. Keresztényi. 2015. “Aspects of storage and corrosion characteristics of biodiesel." Fuel Processing Technology 134:59-64. Diambil (http://dx.doi.org/10.1016/j.fuproc.2015.01.014).

[18] Lewandowski, Z. dan H. Beyenal. 2008. "Mechanisms of Microbially Influenced Corrosion.” Springer Series on Biofilms 35-64.

[19] Lohani, T. K., Barik, P., Patnaik, B. C., \& Mansingh, S. K. 2014 Micro Level Geo-Resistivity Survey through VES Test for Groundwater Feasibility Study and Selection of Bore Well Sites in Pipili Block of Puri. Review of Environment and Earth Sciences, 1(2), 37 45. https://doi.org/10.18488/journal.80/2014.1.2/80.2.37.45

[20] Maruthamuthu, Sundaram et al. 2011. "Microbial corrosion in petroleum product transporting pipelines." Industrial and Engineering Chemistry $\quad$ Research 13 :8006-15. https://doi.org/10.1021/ie1023707.

[21] Monyem, Abdul dan Jon H. Van Gerpen. 2001. "The e ect of biodiesel oxidation on engine performance and emissions." Biomass and Bioenergy 20:317-25. https://doi.org/10.1016/S09619534(00)00095-7.

[22] Rajasekar, A. et al. 2005. "Bacterial degradation of naphtha and its influence on corrosion." Corrosion Science 47(1):257-71. https://doi.org/10.1016/j.corsci.2004.05.016.

[23] Rajasekar, Aruliah dan Yen Peng Ting. 2011. "Role of inorganic and organic medium in the corrosion behavior of bacillus megaterium and pseudomonas sp. in stainless steel SS 304." Industrial and Engineering Chemistry Research 50(22):12534-41. https://doi.org/10.1021/ie200602a

[24] Restrepo-Florez, Juan Manuel, Amarjeet Bassi, Lars Rehmann, dan Michael R. Thompson. 2014. "Investigation of biofilm formation on polyethylene in a diesel/biodiesel fuel storage environment." Fuel 128:240-47. https://doi.org/10.1016/j.fuel.2014.02.052.

[25] Sousa, Diana Z., Hauke Smidt, Maria M. Alves, dan Alfons J. M. Stams. 2009. "Ecophysiology of syntrophic communities that degrade saturated and unsaturated long-chain fatty acids." FEMS Microbiology Ecology 68(3):257-72. https://doi.org/10.1111/j.15746941.2009.00680.x.

[26] Xu, Dake dan Tingyue Gu. 2014. "Carbon source starvation triggered more aggressive corrosion against carbon steel by the Desulfovibrio vulgaris biofilm." International Biodeterioration and Biodegradation 91:74-81. https://doi.org/10.1016/j.ibiod.2014.03.014. 